2

4

6

10

Number of words in main body: 4534

26

Number of references: 59

neutral zone

Running title: Metabolic expansibility

Corresponding author: Lauren Buckley

\title{
Metabolism constrains bird and mammal ranges and predicts shifts in response to climate change
}

$$
\text { Lauren B. Buckley }{ }^{1+} \text {, Imran Khaliq }{ }^{2+} \text {, David L. Swanson }{ }^{3} \text {, and Christian Hof }{ }^{4}
$$

1 Department of Biology, University of Washington, Seattle, WA 98195 USA

2 Zoology Department, Ghazi University, 32200 Punjab, Pakistan

3 Department of Biology, University of South Dakota, Vermillion, SD 57069 USA

4 Senckenberg Biodiversity and Climate Research Centre, Senckenberg Gesellschaft für Naturforschung, 60325 Frankfurt, Germany

Email addresses: 1 Ibuckley@uw.edu, 2 imrankhaliq9@hotmail.com, 3 david.swanson@usd.edu, 4

christian.hof@senckenberg.de

+ authors contributed equally

28 


\section{Abstract}

We test whether physiological constraints on maximum metabolic rate and the factor by which

32 endotherms can elevate their metabolism (metabolic expansibility) govern cold range limits for mammal and bird species.

Global

We examine metabolic expansibility at the cold range boundary $\left(\mathrm{ME}_{\mathrm{CRB}}\right)$ and its trait predictors and then use $\mathrm{ME}_{\mathrm{CRB}}$ to project range shifts for 210 mammal and 61 bird species.

\section{Results}

40 We find evidence for metabolic constraints: the distributions of metabolic expansibility at the cold range boundary peak at similar values for birds (2.7) and mammals (3.2). The right skewed distributions

42 suggest some species have adapted to elevate or evade metabolic constraints. Mammals exhibit greater skew than birds, consistent with their diverse thermoregulatory adaptations and behaviors. Mammal

44 and bird species that are small and occupy low trophic levels exhibit high levels of $\mathrm{ME}_{\mathrm{CRB}}$. Mammals with high $\mathrm{ME}_{\mathrm{CRB}}$ tend to hibernate or use torpor. Predicted metabolic rates at the cold range boundaries represent large energetic expenditures ( $>50 \%$ of maximum metabolic rates). We project species to shift their cold range boundaries poleward by an average of $3.9^{\circ}$ latitude by 2070 .

\section{Main conclusions}

Our analysis suggests that metabolic constraints provide a viable mechanism for projecting cold range

50 boundaries and range shifts in response to climate change for endotherms.

Keywords: distribution, endotherm, metabolic scope, metabolic expansibility, range limit, thermal 


\section{INTRODUCTION}

Environmental temperatures govern the performance and energy use, and ultimately the abundance and distribution, of animals (Bozinovic et al., 2011). Performance and energetic constraints provide a powerful basis for projecting responses to climate change because the constraints should extrapolate better into novel environments than statistical correlations (Radeloff et al., 2015). Models translating environmental conditions into the body temperatures of ectotherms and quantifying limitations on performance and activity durations can robustly predict patterns of abundance and distribution (Kearney \& Porter, 2009; Buckley et al., 2010). The translation is more complex for endothermic animals because they can use endogenous heat production to maintain their body temperatures under a wide range of environmental thermal conditions if available resources and physiological capacities are

64 sufficient (Boyles et al., 2011; McNab, 2012). Thus, few mechanistic approaches predict endotherm distributions (but see examples reviewed in Boyles et al., 2011). Several recent examples employ biophysical models to estimate metabolic constraints, activity limitations, and water balance for focal endotherms (Kearney et al., 2016; Mathewson et al., 2017).

Fundamental physiological constraints on metabolism limit maximum metabolic rate and the factor by which endotherms can elevate their metabolism (Humphries et al., 2004; Stager et al., 2015). An initial test of metabolic constraints (Root, 1988) suggested that the cold range boundaries of passerine birds in

72 North America coincided with winter metabolic rates at the cold range boundary being elevated by a factor of 2.5 over basal rates, but subsequent analyses (Repasky, 1991; Canterbury, 2002) have questioned the generality of metabolic constraints due to the limited biological, distributional, and environmental data available or poor fit between range boundaries and temperature isotherms. 
Physiological measurements indicate metabolic constraints and adaptations. Seasonal cold associated with either climate variability [Climate Variability Hypothesis (Janzen, 1967; Stevens, 1989; Ghalambor et al., 2006)] or seasonal temperature extremes [Cold Adaptation Hypothesis (Swanson \& Garland Jr, 2009)] is expected to select for increased metabolic capacity. Maximum cold-induced metabolic rate ( $\left.\mathrm{M}_{\text {sum }}\right)$ is greater in cold environments (Wiersma et al., 2007) and is phylogenetically conserved

82 (Swanson \& Garland Jr, 2009; Stager et al., 2015). Extensions of classic work examining how animals adapt to regulate heat (Scholander et al., 1950; Scholander, 1955) find that adaptation to environmental conditions alters both basal metabolic rate (BMR) and heat conductance in birds and mammals (Fristoe et al., 2015). Birds and mammals with more poleward range limits that experience colder minimum temperatures can tolerate colder temperatures without elevating metabolism (Khaliq et al., 2015).

88 Here we leverage extensive metabolic, distribution, and phylogenetic datasets (Khaliq et al., 2014; Fristoe et al., 2015) to test the viability of using metabolic constraints to project bird and mammal distributions. Specifically, we estimate the factor by which metabolism is elevated at the cold range boundaries (metabolic expansibility, $\mathrm{ME}_{\mathrm{CRB}}$ ). We expect the distribution of $\mathrm{ME}_{\mathrm{CRB}}$ to be normal and strongly peaked if the cold range edges of birds and mammals are limited by the capacity of their metabolic systems to maintain approximate temperature homeostasis. A peaked distribution would

94 indicate similar limits to $\mathrm{ME}_{\mathrm{CRB}}$ across birds and mammals that differ substantially in geographic distribution, habitat, traits, and life history. However, positive skew in the distribution could reflect species that are metabolically adapted to or able to evade cold conditions. Species may evade extreme temperatures by adjusting activity times (e.g., diurnality) or the maintenance of body temperatures

98 (e.g., use of hibernation or torpor) or by selecting favorable microclimates. We hypothesize that because mammals use strategies to evade full exposure to winter cold (e.g., hibernation, use of subnivean space) to a much greater degree than birds (Swanson, 2010; Williams et al., 2014; Ruf \& 
Geiser, 2015), that mammals will show both greater skew in the density distribution of $\mathrm{ME}_{\mathrm{CRB}}$ and more values of $\mathrm{ME}_{\mathrm{CRB}} /$ Msum approaching or exceeding unity than birds.

We test whether physiological, behavioral and ecological traits (body size, nocturnality, torpor use, diet) associated with adaptation or evasion correspond to higher $\mathrm{ME}_{\mathrm{CRB}}$ values. Body size influences the ability to use potential microclimates as well as metabolic rates and thermal inertia. Trophic levels influence the seasonal availability of food and metabolic rate (McNab, 2008, 2009). We also examine the conservatism of traits and metabolic expansibility at the cold range boundary $\left(\mathrm{ME}_{\mathrm{CRB}}\right)$ across the phylogeny. Finally, evidence for metabolic constraints suggests that (in the absence of adaptation or acclimation) species will follow thermal isoclines through climate change. We thus project ranges and range shifts in response to predicted climate change.

\section{MATERIALS AND METHODS}

114 We estimated the factor by which metabolism is elevated at the cold range boundaries (as in Root, 1988). We calculated metabolic rate $\left(\mathrm{ml} \mathrm{O}_{2} \mathrm{~h}^{-1}\right)$ at the cold range boundary as $M R_{C R B}=\left(T_{I C}-T_{\min }\right) \mathrm{C}+$ $B M R$, where $T_{I c}$ is the lower critical temperatures bounding the lower limit of the thermal neutral zone (TNZ); $T_{\min }$ is the coldest environmental temperatures (see below) at the cold range boundary; BMR is basal metabolic rate $\left(\mathrm{ml} \mathrm{O}_{2} \mathrm{~h}^{-1}\right)$, and $\mathrm{C}$ is thermal conductance $\left(\mathrm{ml} \mathrm{O}_{2} \mathrm{~h}^{-1}{ }^{\circ} \mathrm{C}^{-1}\right)$ (figure 1$)$. We calculated metabolic expansibility at the cold range boundary as $M E_{C R B}=M R_{C R B} / B M R$. We focus on cold range boundaries because they are more likely governed by metabolic constraints than are warm range boundaries (see discussion); at warm range boundaries the capacity for evaporative cooling may be

122 more limiting than the associated metabolic costs and minimal endogenous heating is favored

(Tieleman \& Williams, 2000; McKechnie et al., 2016b). Our estimates of $\mathrm{ME}_{\mathrm{CRB}}$ are approximate in that 
124 they do not account for additional factors such as use of solar radiation, convective heat loss, microclimate variation, and microhabitat selection (Porter \& Kearney, 2009).

126

\section{Data}

128 We restricted our analysis to resident (non-migratory) species. We omitted species on islands and those with latitudinal range limits constrained by continental boundaries. We additionally restricted our analysis to cold range boundaries with temperatures below the $\mathrm{T}_{\mathrm{Ic}}$ (omitted $1 \%$ of species). Accounting for these constraints and limitations on available physiological data, we analyzed 210 and 61 cold range boundaries for mammal and bird species, respectively.

For species distribution data, we used the IUCN range maps for mammals (Patterson et al., 2005) and the BirdLife range maps for birds (BirdLife International and NatureServe, 2014). We calculated temperatures at the range boundaries ( $\mathrm{T}_{\min }$ and $\mathrm{T}_{\max }$ ) using $\mathrm{BIO5}$ (max temperature of warmest month) and BIO6 (min temperature of coldest month) at 5 minute resolution from the WorldClim dataset

138 (Hijmans et al., 2005). Data are interpolated from air temperature at weather stations (generally $2 \mathrm{~m}$ high). Trait data are insufficient to account for microhabitat use (e.g., burrows or under snow), but our trait analysis does provide some indication of exposure to air temperatures. We extracted the grid cells at the northern and southern extremes of the species' distribution for each 5-minute longitudinal band.

142 We quantified the degree to which range boundaries follow temperature isoclines as the standard deviation and median absolute deviation (mad, $\mathrm{R}$ function mad) of cells along the range boundaries.

144 Subsequently, we estimated $T_{\min }$ and $T_{\max }$ as the median of the grid cells along the cold and warm range boundaries, respectively. We checked that minimum and maximum temperatures were sufficiently constant across the range boundaries for our results to be robust to our selection of the median (figure S1). Current data are normals for 1950-2000 and future data are downscaled global climate model 
148 (GCM) projections from CMIP5 (IPCC Fifth Assessment) averaged over 2061-2080. We examined output from both the HadGEM2-AO and CCSM4 models assuming a midrange greenhouse gas concentration scenario (Representative Concentration Pathway RCP6.0, indicates a $6 \mathrm{~W} / \mathrm{m}^{2}$ increase in radiative forcing in 2100 relative to pre-industrial values, http://cmip-pcmdi.Ilnl.gov/cmip5/). Data were accessed using 152 the getData function in the R package raster.

154 The bounds of the TNZ $\left(T_{1 c}\right.$ and $\left.T_{u c},{ }^{\circ} \mathrm{C}\right)$ and body temperature $\left(T_{b},{ }^{\circ} \mathrm{C}\right)$, were compiled from the literature by Khaliq et al. (2014). We incorporated data compiled for additional species (Canterbury, 2002; Riek \& 156 Geiser, 2013; Bozinovic et al., 2014). We used BMR data from Fristoe et al. (2015) and McNab (2008, 2009) after assessing whether the data met criteria for data quality (see below). We extracted Msum data (Msum = BMR + maximum thermogenic capacity) for 20 mammal and 6 bird species from existing compilations (Rezende et al., 2004; Lovegrove, 2005; Swanson \& Garland Jr, 2009; Stager et al., 2015). Those MR values reported in watts were converted to oxygen consumption assuming a factor of $179 \mathrm{ml}$ $\mathrm{O}_{2} \mathrm{~h}^{-1} \mathrm{~W}^{-1}$, which corresponds to lipid metabolism (Schmidt-Nielsen, 1997). Minimum conductance was 162 estimated as the absolute value of the slope of the line connecting $T_{\mathrm{Ic}}$ at $B M R$ to $T_{b}$ when metabolic rate is 0: $\mathrm{Cmin}=\left|(0-B M R) /\left(T_{b}-T_{\mid c}\right)\right|($ Fristoe et al., 2015). We use units of oxygen consumption for metabolism 164 and conductance to align with previous analyses (Fristoe et al., 2015).

166 Analysis of the quality of the data compiled in Khaliq et al. (2014) identified issues with $\mathrm{T}_{\mathrm{uc}}$ but not $\mathrm{T}_{\mathrm{Ic}}$ (McKechnie et al., 2016a). Some $\mathrm{T}_{\text {uc }}$ data are of lesser quality due to small sample sizes or weak measurement protocols (McKechnie et al., 2016a), so we only use the $T_{\text {uc }}$ data for a coarse analysis mentioned in our discussion. We omitted Tuc measurements that were found to be of poor quality ["No UCT" or "NA-" categories; we kept values based on low sample sizes due to the tentative nature of our analyses] (McKechnie et al., 2016a). We revisited the source papers to assess whether the $T_{1 c}$ data were 
172 calculated from valid BMR measurements. We used the following criteria to assess data quality for BMR: measurements were made during the rest phase on inactive individuals in a postabsorptive state. We

174 additionally recorded whether individuals measured were field-collected (or the first generation reared in a laboratory or zoo in a small number of cases) and the location of field collection, as individuals

176 collected far from the range boundary may lack adaptations and acclimation present near the range boundary. We assessed the influence of these quality criteria on our results as described below.

Diet, habitat, and nocturnality data were extracted from Elton Traits (Wilman et al., 2014). Data on whether a species uses torpor or hibernation were extracted from McNab $(2008,2009)$ and Ruf and Geiser (2015). A "torpor" trait was assigned a value of 1 if the species uses either torpor or hibernation and 0 otherwise. Data on relevant thermoregulatory traits such as body shape, insulation, and fur or feather properties were inadequate to include the traits in the analysis.

\section{Analyses}

186 We examine the distribution of $\mathrm{ME}_{\mathrm{CRB}}$ estimates across birds and mammals to assess evidence for a metabolic constraint. We assessed skewness and kurtosis of the $\mathrm{ME}_{\mathrm{CRB}}$ distribution using the skewness metric and D'Agnostino skewness test and Geary metric and Bonett-Seier test in the R moments package. We tested for unimodality in the distributions using Hartigans' dip statistic in the R diptest

190 package. To test whether $\mathrm{ME}_{\mathrm{CRB}}$ varies systematically with $\mathrm{T}_{\min }$ or $\mathrm{T}_{\max }$, we constructed null models for $\mathrm{ME}_{\mathrm{CRB}}$ by randomizing $\mathrm{T}_{\min }$ or $\mathrm{T}_{\max }$ among species and calculating the median and mean $\mathrm{ME}_{\mathrm{CRB}}$ values.

192 We repeated the randomization 1000 times.

194 We then used regressions to assess whether species' traits indicating adaptation to or evasion of cold temperatures can explain variation in $\mathrm{ME}_{\mathrm{CRB}}$. We used model selection based on AICc (dredge function) 
and model averaging (model.avg function in R package MuMIn) to conclude that the best models omitted interactions between the predictor variables (mass, diet, nocturnality, torpor). Accounting for phylogeny did not alter our results, so we report phylogenetic analyses in appendix S1.

We used thermal isoclines (consistent with species maintaining a constant $\mathrm{ME}_{\mathrm{CRB}}$ in the absence of acclimation or adaptation) to project species' distribution in both current and future environments. We restricted predicted distributions to observed west and east longitudinal extents since we have no basis for predicting longitudinal distributions. We identified all pixels with $\mathrm{T}_{\min }$ warmer than the predicted physiological lower temperature limit (based on species-specific observed $\mathrm{ME}_{\mathrm{CRB}}$ ). We removed pixels predicted to be thermally habitable that were geographically isolated from other habitable pixels from our prediction using the clump function in the R package raster. We omitted all clumps with areas less than $5 \%$ of the area of the largest clump, because the core of the predicted distribution is most representative of latitudinal extents. We further restricted our predicted distribution to clumps overlapping with the latitudinal extent of the observed species range. We then quantified the median 210 latitude of grid cells along the cold range edges.

\section{RESULTS}

\section{Metabolic expansibility at the cold range boundary}

214 Our analysis of bird and mammal species with disparate geographic distributions, habitats, traits, and life histories suggest that winter temperatures and the ability to elevate metabolism to maintain body

216 temperatures constrain cold range boundaries (Fig. 2). Cold range boundaries of both mammals $\left(\mathrm{sd}=4.6^{\circ}, \operatorname{mad}=3.9^{\circ}\right.$ of median $\left.\mathrm{T}_{\min }\right)$ and birds $\left(\mathrm{sd}=4.6^{\circ}, \operatorname{mad}=3.3^{\circ}\right.$ of median $\left.\mathrm{T}_{\min }\right)$ approximately follow temperature isoclines (Fig. S1 in the Supporting Information). Translating this thermal variability into metabolic consequences, the median standard deviations represent a change in metabolic rate of 
$12.4 \pm 12.2 \%$ (mean $\pm \mathrm{sd}$ ) for mammals and $10.8 \pm 7.8 \%$ for birds. The distributions of metabolic expansibility, $\mathrm{ME}_{\mathrm{CRB}}$, are peaked and peaks occur at similar values for birds and mammals. The bird distribution has a slight dip at the peak of the density distribution, which we attribute to limited sample size in the absence of evidence for non-unimodality (Hartigans' dip test: $D=0.05, p=0.3$ ). We thus

224 estimate the peak value as the mean of the two subpeaks. The density distribution of $\mathrm{ME}_{\mathrm{CRB}}$ peaks at 2.72 for birds (median=3.21, mean $\pm s d=3.28 \pm 1.63$ ) and at a slightly higher value $(3.17$, median=3.63, mean $\pm s d=4.64 \pm 3.35$ ) for mammals. $M_{C R B}$ values fall outside the $95 \%$ confidence intervals of the null model estimated by randomization for both mammals (median: 3.53-3.54, mean:4.55-4.56) and birds

228 (median: 2.63-2.64, mean:3.16-3.17). The previous value found for birds (2.5 x BMR; Root, 1988) was similar to our estimate of the peak of the distribution.

We assessed whether ranges may be constrained more strongly by maximum metabolic capacity ( $\mathrm{M}_{\text {sum }}$ ) rather than the factorial capacity for elevating metabolism over BMR ( $\left.\mathrm{ME}_{\mathrm{CRB}}\right)$. Among the limited data available for our focal species ( $N=20$ mammal and 6 bird species), $M_{\text {sum }}$ is on average 5.0 times $B M R$

234 (median $5.4,25^{\text {th }}$ to $75^{\text {th }}$ percentile= 4.0 to 6.3 ). The density distribution of the ratio of $M_{\text {CRB }}$ to $M_{\text {sum }}$ peaks at 0.7 (median=0.88, mean $\pm s d=0.96 \pm 0.44$, Fig. 3 ).

The right skewed distributions of $\mathrm{ME}_{\mathrm{CRB}}$ (Fig. 2) suggest that some species have evolved the capacity to maintain a higher $\mathrm{ME}_{\mathrm{CRB}}$ or to evade the constraints of cold temperatures via torpor, microclimate selection, or movement. The distribution for mammals is more skewed (2.54) than that for birds (1.06), but both exhibit significant positive skew (D’Agnostino test, mammals: $z=9.52, p<10-{ }^{15}$; birds: $z=3.22$, p<0.001). Only mammals exhibit significantly more kurtosis than expected under normality (Bonett- 
244 We next assess whether traits that allow organisms to maintain high metabolism or evade cold temperature can explain the skewed distribution. Mammalian traits (mass, diet, nocturnality, and use of torpor or hibernation) account for a substantial portion of variation in $\operatorname{ME}_{C R B}\left(r^{2}=0.29, F_{[7,171]}=11.2\right.$, $\mathrm{p}<0.001)$; mammal species that are relatively small $(\mathrm{t}=-4.36, \mathrm{p}<0.001)$ and use torpor or hibernation

$248(\mathrm{t}=4.99, \mathrm{p}<0.001)$ tend to have higher $\mathrm{ME}_{\mathrm{CRB}}$ (Fig. 2, Table S1). Diet also significantly influences $\mathrm{ME}_{\mathrm{CRB}}$, with granivores having higher $\mathrm{ME}_{\mathrm{CRB}}$ than mammals consuming other diets $(\mathrm{F}=2.44, \mathrm{p}<0.05, \mathrm{ANOVA}$,

Table S3). Bird traits (mass, diet, and nocturnality) likewise account for a substantial portion of variation in $\mathrm{ME}_{\mathrm{CRB}}\left(\mathrm{r}^{2}=0.28, \mathrm{~F}_{[6,54]}=4.9, \mathrm{p}<0.001\right)$; birds that are small $(\mathrm{t}=-2.82, \mathrm{p}<0.05)$ tend to have higher $\mathrm{ME}_{\mathrm{CRB}}$.

252 Birds that eat invertebrates or plants and seeds exhibit higher $\mathrm{ME}_{\mathrm{CRB}}$ than those consuming other diets $(F=7.85, p<0.01, A N O V A)$. Limited phylogenetic signal in mammal and bird $\mathrm{ME}_{C_{R B}}$ (Fig. S3) arises largely

254 from conservatism of predictor traits (appendix S1). Phylogenetic regressions do not substantially deviate from linear regressions (Table S1, appendix S1).

\section{Data quality}

258 In our full dataset for mammal $\mathrm{ME}_{\mathrm{CRB}}$, the following proportions of species with data met our BMR quality control criteria: 93.9\% [58.6\% including NA (not available) values as not meeting quality criteria] were measured during the resting phase, $70.0 \%$ (42.9\% including NA values) were postabsorptive, and 81.2\% were wild-caught (70.0\% including NA values) (Table S2). Of the quality criteria, only whether the mammal species was live-trapped or captive was a significant predictor of $\mathrm{ME}_{\mathrm{CRB}}$ (resting phase:

$F_{[1,82]}=1.53, p=0.22$; postabsorptive: $F_{[1,82]}=0.04 p=0.84$; wild caught: $\left.F_{[1,82]}=5.15, p<0.05\right)$. However, 264 restricting the dataset to wild-caught species does not substantially alter the peak value of metabolic expansibility (peak=3.27, mean $=4.72$, median $=3.75$ ). The trait predictors of $\mathrm{ME}_{\mathrm{CRB}}$ remain similar when considering only wild-caught individuals (Table S3). 
In our full dataset for bird $\mathrm{ME}_{\mathrm{CRB}}$, the following proportions of species with data met our BMR quality criteria: $93.0 \%$ (86.9\% including species without data) were measured during the resting phase, $88.9 \%$

270 (52.4\% including species without data) were postabsorptive, and 68.9\% were wild-caught (50.8\% including species without data) (Table S2). Similar to mammals, of the quality criteria only whether the

272 bird species was live-trapped or captive was a significant predictor of $\mathrm{ME}_{\mathrm{CRB}}$ (resting phase: $\mathrm{F}_{[1,32]}=0.00$, $p=0.94$; postabsorptive: $F_{[1,32]}=0.68 p=0.42$; wild caught: $\left.F_{[1,32]}=6.90, p<0.05\right)$. However, restricting the

274 dataset to wild-caught species did not substantially alter the peak value of $M E_{C R B}(p e a k=2.60$, mean= 3.07, median= 3.11). The trait predictors of $M E_{C R B}$ remained similar, but some predictors lose

276 significance, when considering only wild-caught individuals (Table S3).

278 The measured individuals were collected throughout the species' range with average positions near the center of the range for both mammals (median and mean from range edge: $10.3^{\circ}$ and $13.4^{\circ}$ latitude, $47.2 \%$ and $49.4 \%$ of the species' latitudinal range) and birds (median and mean from range edge: $18.3^{\circ}$ and $20.4^{\circ}$ latitude, $50.8 \%$ and $49.9 \%$ of the species' latitudinal range). Neither distance metric is a

282 significant predictor of $\mathrm{ME}_{\mathrm{CRB}}$ in mammals (distance: $F_{[1,142]}=0.27, p=0.60 ;$ percent: $F_{[1,142]}=0.10, p=0.76$ ) or birds (distance: $F_{[1,29]}=0.12 p=0.73$; percent: $F_{[1,29]}=0.39 p=0.54$ ). Collection locations have a median 284 elevation of $275 \mathrm{~m}\left(25^{\text {th }}\right.$ and $75^{\text {th }}$ quantiles: 39 to $849 \mathrm{~m}$, based on collection coordinates and Google Maps Elevation API). Thus, few of the physiological measurements reflect metabolic adaptation to high 286 elevation.

\section{Range shifts}

We forecast potential range shifts by examining how metabolic constraints will shift through climate change. For example, North American rodent species differ in their metabolic constraints, the extents of their current distribution, and the projected range expansion as a result of climate change (Fig. 4 for 
projections using the HadGEM2-AO model; Fig. S4 for CCSM4 model projections). The quality of the range projections vary across species (Figs. S5-S8). We predict that most mammals and birds will shift their cold range boundaries poleward through climate changes (Fig. 4). We project a similar magnitude of cold range boundary shifts for mammals (mean $=3.77^{\circ}$, median $\left.=2.58^{\circ}\right)$ and birds $\left(\right.$ mean $=4.20^{\circ}$, median $\left.=3.63^{\circ}\right)$. Numerous species are projected to shift their cold range boundary poleward by $6^{\circ}$ latitude ( $75 \%$ quantile) and some species are predicted to shift by as much as $22^{\circ}$ (Fig. 4).

\section{DISCUSSION}

Our analysis supports a mechanism underlying observations that endotherms track thermal isotherms through climate change (Tingley et al., 2009; Chen et al., 2011). However, many observed range shifts have been idiosyncratic in extent and direction (Gibson-Reinemer \& Rahel, 2015). Filtering the range shifts through the lens of metabolic constraints may resolve some discrepancies. Our data are consistent with the poleward range edges of both birds and mammals being constrained by the factor by which they can elevate their metabolism above basal rates (perhaps resulting from a constraint on maximum metabolic rates). The constraint may result from either direct physiological limitations on metabolism, such as the ability to sustain high rates of thermogenesis over prolonged periods, or limitations on energy acquisition. The rates of $M E_{C R B}$ that we find for birds (peak of distribution=2.7) are similar to a previous value (2.5) for a more taxonomically and geographically restricted analysis (Root, 1988).

312 We find a slightly higher peak of the $\mathrm{ME}_{\mathrm{CRB}}$ distribution for mammals (3.2). The distribution of $M E_{C R B}$ is right skewed, more so for mammals than for birds. The greater skew in the mammal $\mathrm{ME}_{\mathrm{CRB}}$ distribution

314 is consistent with the prominent use of hibernation and protected microclimates (e.g., burrows, dens, subnivean space) during winter in mammals, but lesser use of these options to avoid cold thermal 
environments in birds (Swanson, 2010; Ruf \& Geiser, 2015). These adjustments have the effect of rendering the thermal conditions encountered at the $\mathrm{ME}_{\mathrm{CRB}}$ as less extreme than the actual ambient conditions, which results in an overestimation of the thermal isocline followed by the cold range boundary. In addition, differences in the mechanisms of thermoregulation between mammals and birds may contribute to the difference in ME. Cold-adapted mammals have well developed capacities for nonshivering thermogenesis through brown fat, but birds lack brown fat and although they may possess some muscular non-shivering thermogenesis, muscular shivering appears to be the primary mechanism of heat production in birds (Mezentseva et al., 2008).

The limited data on maximum cold-induced metabolic capacity $\left(\mathrm{M}_{\text {sum }}\right)$ provide additional support for a metabolic constraint. We estimate that thermoregulation at the cold range boundary requires a substantial proportion (>50\%) of the potential metabolic capacity for thermogenesis of the species. This supports the existence of a metabolic constraint on range boundaries and suggests that species use a substantial portion of their maximum metabolic capacity to thermoregulate. The right skewed distribution (and instances where $M R_{C B} / M_{\text {sum }}>1$ ) suggests that some species use torpor or hibernation or evade the coldest temperatures through habitat and microclimate selection (Fig. 3). Because $\mathrm{M}_{\text {sum }}$ is a

332 flexible trait correlated with environmental conditions (Rezende et al., 2004; Swanson, 2010), ratios approaching or exceeding one may also result from $\mathrm{M}_{\text {sum }}$ measurement occurring for populations in warmer climates than those at the cold range boundary. Correlations between $\mathrm{M}_{\text {sum }}$ and environmental temperatures have been previously documented for rodents (Rezende et al., 2004; Bozinovic et al., 2011) and birds (Swanson, 2010; Stager et al., 2015).

338 We identify traits associated with high values for $\mathrm{ME}_{\mathrm{CRB}}$, which may be adaptations to or consequences of inhabiting cold environments. Body mass is an important factor that influences $\mathrm{ME}_{\mathrm{CRB}}$. Smaller 
mammals, which tend to exhibit greater $\mathrm{ME}_{\mathrm{CRB}}$, may be able to evade cold temperatures through seeking shelters or selecting favorable microclimates. Alternatively, the ability to use torpor or

342 hibernation enables mammals to inhabit colder environments. Mammals using torpor tend to be small, which may contribute to the relationship between mass and $\mathrm{ME}_{\mathrm{CRB}}$ (Ruf \& Geiser, 2015). Small

344 mammals may also be able to meet the resource requirements or store energy to maintain high metabolism through cold periods (due to the low per-organism, or total, metabolic rate stemming from

346 their small size) (Humphries et al., 2004; Angilletta et al., 2010). Mammals at lower trophic levels (herbivores and invertebrate consumers) tend to exhibit higher $\mathrm{ME}_{\mathrm{CRB}}$. These species tend to have lower 348 BMR (Khaliq et al., 2014, 2015) and their food sources may be more consistently available. Lower mass-specific rates of heat production and heat loss (conductance) and smaller surface area to volume ratios favor larger body sizes in colder environments (i.e., Bergmann's hypothesis, Ashton et al., 352 2000). Regardless, birds' and mammals' body sizes are diverse across climates (Khaliq et al., 2014; Fristoe et al., 2015). An analysis of regression residuals suggests that adaptations to cold environments 354 in birds and mammals results in increased BMR and reduced conductance (Fristoe et al., 2015). Our analysis suggests that greater values of $\mathrm{ME}_{\mathrm{CRB}}$ (perhaps associated with selection for higher $\mathrm{M}_{\text {sum }}$ ) enable 356 small birds and mammals to inhabit cooler environments. Birds from cold climates tend to exhibit higher $\mathrm{M}_{\text {sum }}$ (Stager et al., 2015). We identify traits (small body size, use of torpor or hibernation, diet) 358 that may enable the elevated $\mathrm{ME}_{\mathrm{CRB}}$.

360 We omit analysis of warm range boundaries because we estimated that $61 \%$ and $45 \%$ of mammal and bird species with unconstrained warm range boundaries, respectively, do not experience $T_{\max }$ values 362 exceeding their $\mathrm{T}_{\text {uc. }}$. We note that these values are likely an overestimate because they do not account for heat associated with solar radiation or heat extremes, but they do suggest a greater viability for 
using metabolic constraints to project cold range boundaries. Our estimates of metabolic expansibility at the warm range boundry (for species with $\mathrm{T}_{\max }>\mathrm{T}_{\mathrm{uc}}$, following methodology for $\mathrm{ME}_{\mathrm{CRB}}$ ) approximate 1 , highlighting the physiological challenges of heat dissipation (Weathers, 1981). At warm range boundaries, the capacity for evaporative cooling may be more limiting than the associated metabolic costs and minimal endogenous heating is favored (Tieleman \& Williams, 2000; McKechnie et al., 2016b). Evaporative cooling poses a risk of dehydration in response to short term heat stress (McKechnie et al., 370 2012) and presents a challenge for longer term water balances (Kearney et al., 2016). Additionally, other biotic factors such as species interactions and resource or habitat constraints often constrain 372 warm range boundaries (Sexton et al., 2009).

374 The observation that many species do not currently face metabolic constraints at their warm range boundaries suggests that direct temperature effects on metabolism resulting from climate change may predominately expand cold range boundaries rather than contract warm range boundaries. However, the increase in extreme heat events associated with climate change will likely result in range contractions via thermal stress (McKechnie \& Wolf, 2009; Buckley \& Huey, 2016). Range contractions at warm range boundaries may primarily result from indirect effects (e.g., species' interactions), which often predominate in climate change responses (Tylianakis et al., 2008; Walther, 2010).

382 Assuming species follow thermal isoclines due to metabolic constraints, we project that species will shift their cold range boundaries poleward by an average of $3.9^{\circ}$ latitude with numerous species shifting by $6^{\circ}$ 384 (75\% quantile). Our analyses suggest that hibernation and torpor are important determinants of cold range boundaries. Climate change will also likely alter the energetics of hibernation, which may amplify poleward range shifts (Humphries et al., 2002). Many bird and mammal species rely on seasonal migration to obtain resources to meet seasonal energetic demands; considering the costs and benefits 
of such movements will be important to forecasting responses to climate change among migratory birds and mammals (which we excluded from our analysis) (Robinson et al., 2009). Shifting activity times may also function to modify estimates of range shifts (Levy et al., 2012).

Our analysis of a taxonomically and geographically diverse dataset suggests that metabolic constraints provide a viable mechanism for projecting the poleward range boundaries of endotherms. We hold that the Scholander-Irving model we employ provides a useful approximation of metabolism, but highlight several considerations that may improve upon the analyses. We estimate metabolic costs assuming homeothermy, but accumulating data suggest that endotherms represent a continuum of heterothermy (Boyles et al., 2013). Consideration of the occurrence of torpor/hibernation in the present study likely only partially accounted for deviations from thermoregulation due to $T_{b}$ variation. Many endotherms seasonally acclimatize their insulation, behavior, and physiology (Boyles et al., 2011; Bozinovic et al., 2011). Some metabolic estimates in our database are specific to the cold season, but we did not fully account for acclimatization. A comparison of BMR and field metabolic rates (FMR) for small mammals

402 failed to find support for intrinsic limitations on metabolism and low FMRs in very cold climates indicated acclimatization including behavioral avoidance (Humphries et al., 2005). Over longer time periods, adaptation may alter morphology or metabolic constraints (Boyles et al., 2011). Behavioral strategies for buffering cold include sheltering, huddling, basking, and microclimate selection (Angilletta et al., 2010). Despite these complications, metabolic constraints provide an initial step towards generalizable and mechanistic projections of endotherm responses to climate change.

\section{Acknowledgements}

410 We thank N. Bouzid, A. Cannistra, S. Graham, J. HilleRisLambers and R. Huey for constructive input; T. Root for an introduction to metabolic constraints; and those who collected, compiled, and disseminated

412 the data we used. We thank A. McKechnie for suggestions on assessing data quality. This work was supported by the National Science Foundation [DBI-1349865 to L.B.B. and OIA-1632810 to D.L.S.]. 


\section{Data accessibility}

\section{8}

420

422

\section{Supporting Information}

Appendix S1. Phylogenetic analysis.

426 Appendix S2. Data description.

Appendix S3. Data.

428 Table S1. Regression model results.

Table S2. Summary of data quality.

430 Table S3. Regression model results for live trapped animals.

Figure S1. Comparison of range edge temperature metrics.

432 Figure S2. Metabolic expansibility at the warm range edge.

Figure S3. Phylogenetic conservatism of metabolic expansibility and mass.

434 Figure S4. Range projections using CCSM4 climate projections.

Figure S5-S8. Range projections for all species.

436

438

\section{References} endotherms. Fronteirs in Bioscience, 2, 861-881. Naturalist, 156, 390-415. International, Cambridge, UK and NatureServe, Arlington, USA.,. Annual Review of Ecology, Evolution, and Systematics, 42, 155-179. Research, 16, 143-152. implications for organismal vulnerabilities. Global Change Biology, 22, 3829-3842. mechanism inform species' distribution models? Ecology Letters, 13, 1041-1054. 83, 946-957. associated with high levels of climate warming. Science, 333, 1024-1026.

Angilletta, M.J., Cooper, B.S., Schuler, M.S. \& Boyles, J.G. (2010) The evolution of thermal physiology in

Ashton, K.G., Tracy, M.C. \& de Queiroz, A. (2000) Is Bergmann's rule valid for mammals? American

BirdLife International and NatureServe (2014) Bird species distribution maps of the world. BirdLife

Boyles, J.G., Seebacher, F., Smit, B. \& McKechnie, A.E. (2011) Adaptive thermoregulation in endotherms may alter responses to climate change. Integrative and Comparative Biology, 51, 676-690.

Boyles, J.G., Thompson, A.B., McKechnie, A.E., Malan, E., Humphries, M.M. \& Careau, V. (2013) A global heterothermic continuum in mammals. Global ecology and biogeography, 22, 1029-1039.

Bozinovic, F., Calosi, P. \& Spicer, J.I. (2011) Physiological correlates of geographic range in animals.

Bozinovic, F., Ferri-Yáñez, F., Naya, H., Araújo, M.B. \& Naya, D.E. (2014) Thermal tolerances in rodents: species that evolved in cold climates exhibit a wider thermoneutral zone. Evolutionary Ecology

Buckley, L.B. \& Huey, R.B. (2016) Temperature extremes: geographic patterns, recent changes, and

Buckley, L.B., Urban, M.C., Angilletta, M.J., Crozier, L.G., Rissler, L.J. \& Sears, M.W. (2010) Can

Canterbury, G. (2002) Metabolic adaptation and climatic constraints on winter bird distribution. Ecology,

Chen, I., Hill, J.K., Ohlemüller, R., Roy, D.B. \& Thomas, C.D. (2011) Rapid range shifts of species 
Fristoe, T.S., Burger, J.R., Balk, M.A., Khaliq, I., Hof, C. \& Brown, J.H. (2015) Metabolic heat production and thermal conductance are mass-independent adaptations to thermal environment in birds and mammals. Proceedings of the National Academy of Sciences, 112, 15934-15939.

Ghalambor, C.K., Huey, R.B., Martin, P.R., Tewksbury, J.J. \& Wang, G. (2006) Are mountain passes higher in the tropics? Janzen's hypothesis revisited. Integrative and Comparative Biology, 46, 5-17.

Gibson-Reinemer, D.K. \& Rahel, F.J. (2015) Inconsistent range shifts within species highlight idiosyncratic responses to climate warming. PloS one, 10, e0132103.

Hijmans, R.J., Cameron, S.E., Parra, J.L., Jones, P.G. \& Jarvis, A. (2005) Very high resolution interpolated climate surfaces for global land areas. International Journal of Climatology, 25, 1965-1978.

Humphries, M.M., Boutin, S., Thomas, D.W., Ryan, J.D., Selman, C., McAdam, A.G., Berteaux, D. \& Speakman, J.R. (2005) Expenditure freeze: the metabolic response of small mammals to cold environments. Ecology Letters, 8, 1326-1333.

Humphries, M.M., Thomas, D.W. \& Speakman, J.R. (2002) Climate-mediated energetic constraints on the distribution of hibernating mammals. Nature, 418, 313-316.

Humphries, M.M., Umbanhowar, J. \& McCann, K.S. (2004) Bioenergetic prediction of climate change impacts on northern mammals. Integrative and Comparative Biology, 44, 152-162.

Janzen, D.H. (1967) Why mountain passes are higher in the tropics. American Naturalist, 101, 233-249.

Kearney, M. \& Porter, W. (2009) Mechanistic niche modelling: combining physiological and spatial data to predict species' ranges. Ecology Letters, 12, 334-350.

Kearney, M.R., Porter, W.P. \& Murphy, S.A. (2016) An estimate of the water budget for the endangered night parrot of Australia under recent and future climates. Climate Change Responses, 3, 14.

Khaliq, I., Fritz, S.A., Prinzinger, R., Pfenninger, M., Böhning-Gaese, K. \& Hof, C. (2015) Global variation in thermal physiology of birds and mammals: evidence for phylogenetic niche conservatism only in the tropics. Journal of Biogeography, 42, 2187-2196.

Khaliq, I., Hof, C., Prinzinger, R., Böhning-Gaese, K. \& Pfenninger, M. (2014) Global variation in thermal tolerances and vulnerability of endotherms to climate change. Proceedings of the Royal Society B: Biological Sciences, 281, 20141097.

Levy, O., Dayan, T., Kronfeld-Schor, N. \& Porter, W.P. (2012) Biophysical modeling of the temporal niche: from first principles to the evolution of activity patterns. The American Naturalist, 179, 794-804.

Lovegrove, B.G. (2005) Seasonal thermoregulatory responses in mammals. Journal of Comparative Physiology B, 175, 231-247.

Mathewson, P.D., Moyer-Horner, L., Beever, E.A., Briscoe, N.J., Kearney, M., Yahn, J.M. \& Porter, W.P. (2017) Mechanistic variables can enhance predictive models of endotherm distributions: the American pika under current, past, and future climates. Global Change Biology, 23, 1048-1064.

McKechnie, A.E., Coe, B.H., Gerson, A.R. \& Wolf, B.O. (2016a) Data quality problems undermine analyses of endotherm upper critical temperatures. Journal of Biogeography, 10.1111/jbi.12941.

McKechnie, A.E., Hockey, P.A. \& Wolf, B.O. (2012) Feeling the heat: Australian landbirds and climate change. Emu, 112, i-vii.

McKechnie, A.E., Whitfield, M.C., Smit, B., Gerson, A.R., Smith, E.K., Talbot, W.A., McWhorter, T.J. \& Wolf, B.O. (2016b) Avian thermoregulation in the heat: efficient evaporative cooling allows for extreme heat tolerance in four southern Hemisphere columbids. Journal of Experimental Biology, jeb-138776.

McKechnie, A.E. \& Wolf, B.O. (2009) Climate change increases the likelihood of catastrophic avian mortality events during extreme heat waves. Biology Letters, 6, 253-256.

McNab, B.K. (2008) An analysis of the factors that influence the level and scaling of mammalian BMR. Comparative Biochemistry and Physiology Part A: Molecular \& Integrative Physiology, 151, 5-28. Biochemistry and Physiology Part A: Molecular \& Integrative Physiology, 152, 22-45. 
McNab, B.K. (2012) Extreme measures: the ecological energetics of birds and mammals, University of Chicago Press, Chicago.

Mezentseva, N.V., Kumaratilake, J.S. \& Newman, S.A. (2008) The brown adipocyte differentiation pathway in birds: an evolutionary road not taken. BMC biology, $6,1$.

Patterson, B.D., Ceballos, G., Sechrest, W., Tognelli, M.F., Brooks, T., Luna, L., Ortega, P., Salazar, I. \& Young, B.E. (2005) Digital distribution maps of the mammals of the Western Hemisphere, version 2.0. NatureServe, Arlington, $V A$.

518 Radeloff, V.C., Williams, J.W., Bateman, B.L., Burke, K.D., Carter, S.K., Childress, E.S., Cromwell, K.J., Gratton, C., Hasley, A.O., Kraemer, B.M. \& others (2015) The rise of novelty in ecosystems. Ecological Applications, 25, 2051-2068.

Repasky, R.R. (1991) Temperature and the northern distributions of wintering birds. Ecology, 72, 22742285.

Rezende, E.L., Bozinovic, F. \& Garland, Theodore (2004) Climatic adaptation and the evolution of basal and maximum rates of metabolism in rodents. Evolution, 58, 1361-1374.

Riek, A. \& Geiser, F. (2013) Allometry of thermal variables in mammals: consequences of body size and phylogeny. Biological Reviews, 88, 564-572.

Robinson, R.A., Crick, H.Q., Learmonth, J.A., Maclean, I., Thomas, C.D., Bairlein, F., Forchhammer, M.C., Francis, C.M., Gill, J.A., Godley, B.J. \& others (2009) Travelling through a
change and migratory species. Endangered Species Research, 7, 87-99.

Root, T. (1988) Energy constraints on avian distributions and abundances. Ecology, 69, 330-339.

Ruf, T. \& Geiser, F. (2015) Daily torpor and hibernation in birds and mammals. Biological Reviews, 90, 891-926.

Schmidt-Nielsen, K. (1997) Animal physiology: adaptation and environment, Cambridge University Press.

Scholander, P.F. (1955) Evolution of climatic adaptation in homeotherms. Evolution, 9, 15-26.

Scholander, P.F., Hock, R., Walters, V., Johnson, F. \& Irving, L. (1950) Heat regulation in some arctic and tropical mammals and birds. The Biological Bulletin, 99, 237-258.

Sexton, J.P., Mclntyre, P.J., Angert, A.L. \& Rice, K.J. (2009) Evolution and ecology of species range limits. Annual Review of Ecology, Evolution, and Systematics, 40, 415-436.

Stager, M., Pollock, H.S., Benham, P.M., Sly, N.D., Brawn, J.D. \& Cheviron, Z.A. (2015) Disentangling environmental drivers of metabolic flexibility in birds: the importance of temperature extremes versus temperature variability. Ecography, 39, 787-795.

Stevens, G.C. (1989) The latitudinal gradient in geographical range: how so many species coexist in the tropics. American Naturalist, 133, 240-256.

544 Swanson, D.L. (2010) Seasonal metabolic variation in birds: functional and mechanistic correlates. Current Ornithology Volume 17, pp. 75-129. Springer.

Swanson, D.L. \& Garland Jr, T. (2009) The evolution of high summit metabolism and cold tolerance in birds and its impact on present-day distributions. Evolution, 63, 184-194.

Tieleman, B.I. \& Williams, J.B. (2000) The adjustment of avian metabolic rates and water fluxes to desert environments. Physiological and Biochemical Zoology, 73, 461-479.

550 Tingley, M.W., Monahan, W.B., Beissinger, S.R. \& Moritz, C. (2009) Birds track their Grinnellian niche through a century of climate change. Proceedings of the National Academy of Sciences, 106,

552 19637-19643.

Tylianakis, J.M., Didham, R.K., Bascompte, J. \& Wardle, D.A. (2008) Global change and species

$554 \quad$ interactions in terrestrial ecosystems. Ecology Letters, 11, 1351-1363.

Walther, G.-R. (2010) Community and ecosystem responses to recent climate change. Philosophical Transactions of the Royal Society B: Biological Sciences, 365, 2019-2024. 
Weathers, W.W. (1981) Physiological thermoregulation in heat-stressed birds: consequences of body size. Physiological Zoology, 54, 345-361.

Wiersma, P., Muñoz-Garcia, A., Walker, A. \& Williams, J.B. (2007) Tropical birds have a slow pace of life. Proceedings of the National Academy of Sciences, 104, 9340-9345.

Williams, C.M., Henry, H.A. \& Sinclair, B.J. (2014) Cold truths: how winter drives responses of terrestrial organisms to climate change. Biological Reviews, 90, 214-235.

Wilman, H., Belmaker, J., Simpson, J., de la Rosa, C., Rivadeneira, M.M. \& Jetz, W. (2014) EltonTraits 1.0: Species-level foraging attributes of the world's birds and mammals. Ecology, 95, 2027-2027.

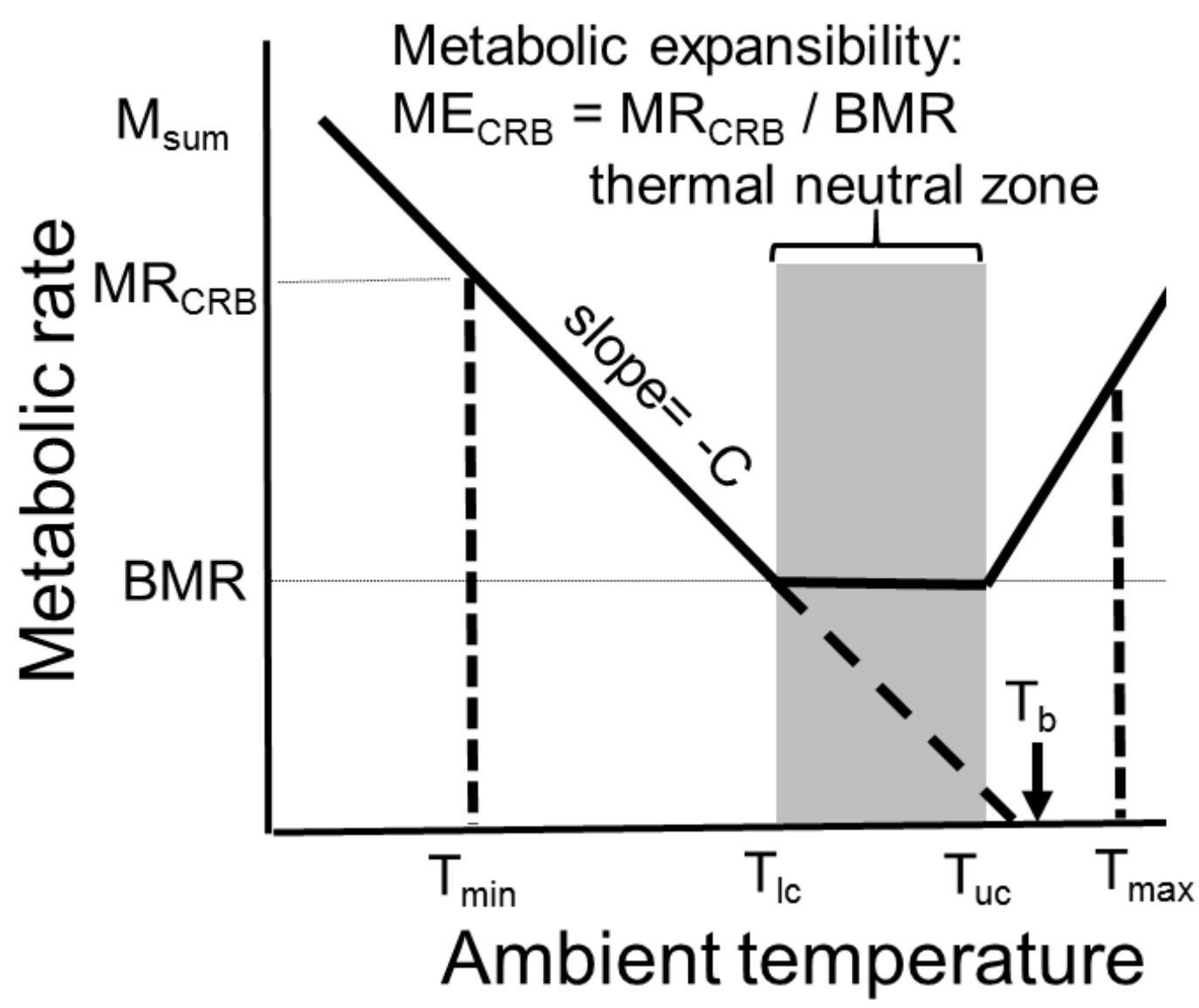

Figure 1. How ambient temperature governs metabolic rate. The thermal neutral zone [bounded by lower $\left(T_{\mathrm{Ic}}\right)$ and upper ( $\left.T_{\mathrm{uc}}\right)$ critical temperatures] is the range of temperatures over which endotherms are able to maintain their basal metabolic rate (BMR). We use the minimum ( $\left.T_{\min }\right)$ and maximum $\left(T_{\max }\right)$ ambient temperatures across a species' range to estimate sustained metabolic rate at the range boundary ( $\left.M R_{C R B}\right)$. We calculate metabolic expansibility $\left(M E_{C R B}\right.$ ) as $M R_{C R B} / B M R$ and depict maximum metabolic capacity $\left(\mathrm{M}_{\text {sum }}\right)$. Thermal conductance $(C)$ is calculated as the slope of the line terminating at body temperature $\left(T_{b}\right)$. 

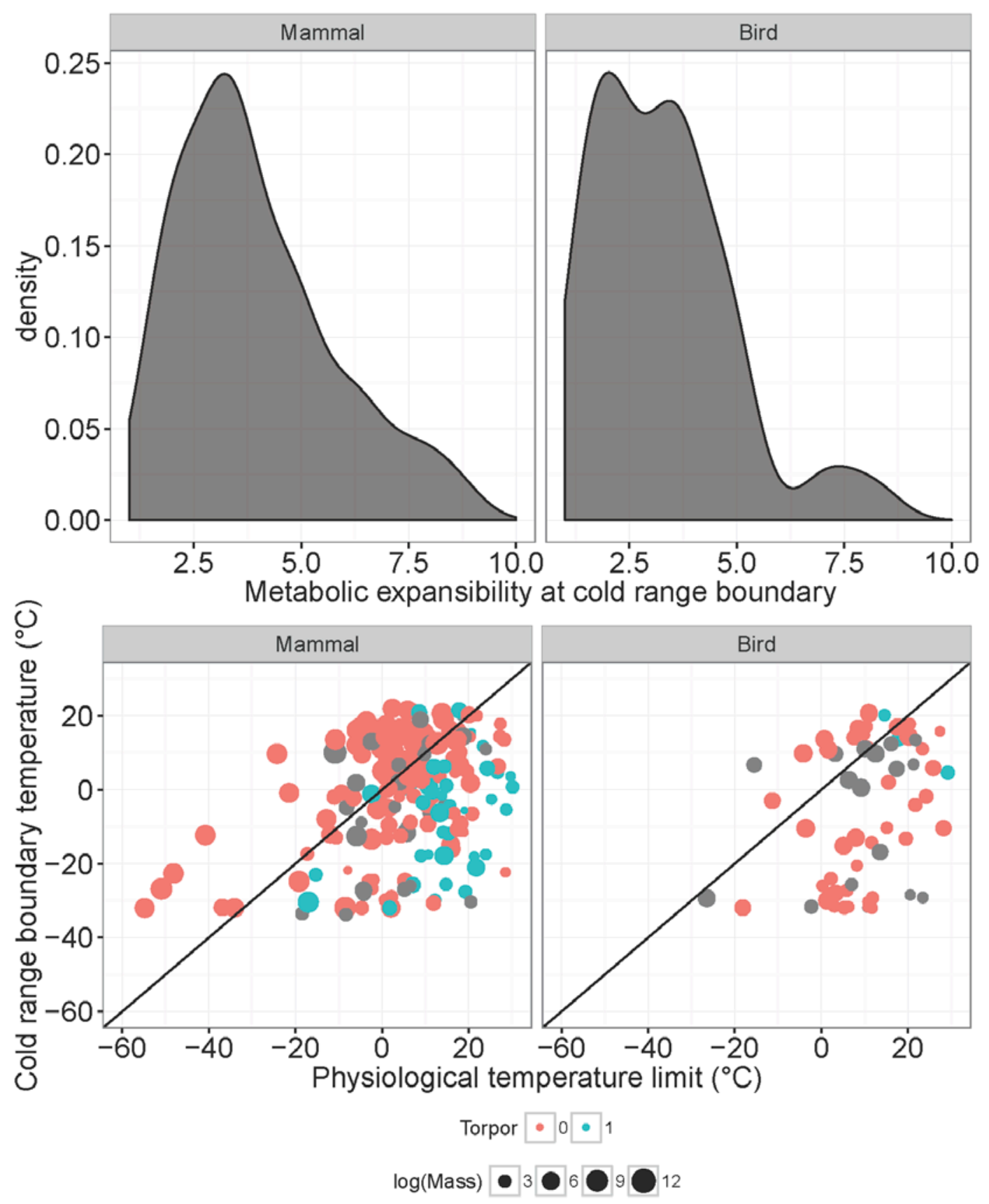

578 Figure 2. The density distribution of metabolic expansibility, $M_{C R B}$ (the factor by which metabolic rate at the cold range edge is elevated over basal metabolic rate) peaks at similar values for birds and mammals

580 (a). We examine interspecific variation in $\mathrm{ME}_{\mathrm{CRB}}$ by (b) plotting the physiological temperature limit predicted by assuming the mode of $\mathrm{ME}_{\mathrm{CRB}}$ and the observed temperatures at the cold range boundaries. Mammals and birds that are small (symbol size) and use torpor or hibernation (color, 1=use, gray=no data) tend to be found in environments colder than predicted assuming the mode $M_{C R B}$ (i.e., they have higher $\mathrm{ME}_{\mathrm{CRB}}$ ). 

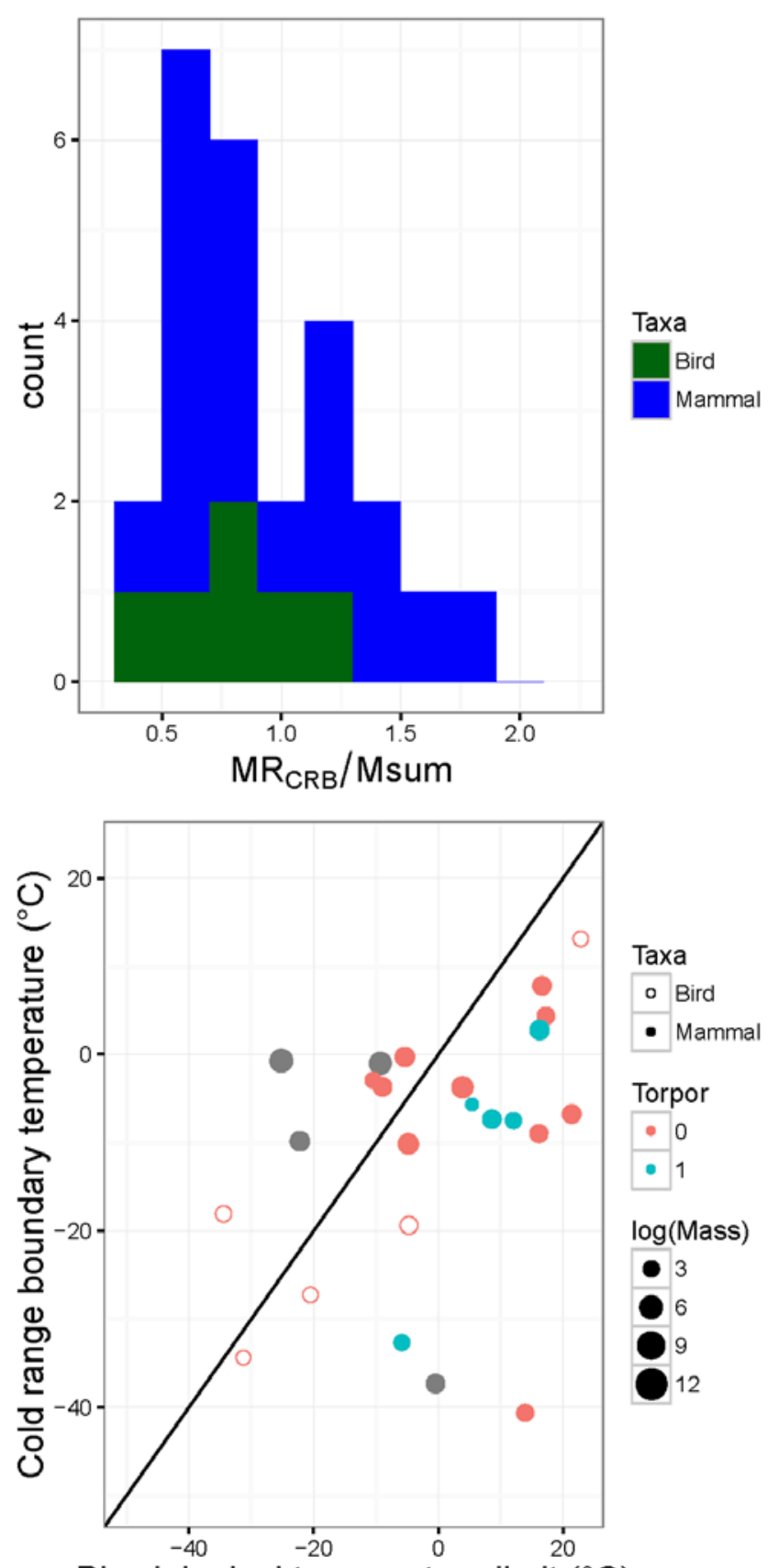

Physiological temperature limit $\left({ }^{\circ} \mathrm{C}\right)$

Figure 3. A histogram (a) of the ratio of maximum metabolic capacity ( $\left.M_{\text {sum }}\right)$ to estimated metabolic rate at the cold range boundary ( $\mathrm{MR}_{\mathrm{CRB}}$ ) suggests the high energetic demands of thermoregulation. We examine interspecific variation in the ratio $\left(M_{\mathrm{CRB}} / \mathrm{M}_{\text {sum }}\right)$ by plotting the observed temperatures at the cold range boundaries against the physiological temperature limit corresponding to $M R_{C R B}=0.7 M_{\text {sum }}$ (b). We depict mammals (filled circles) and birds (hollow circles), mass (symbol size), and use of torpor or hibernation (color, 1 indicates use). 

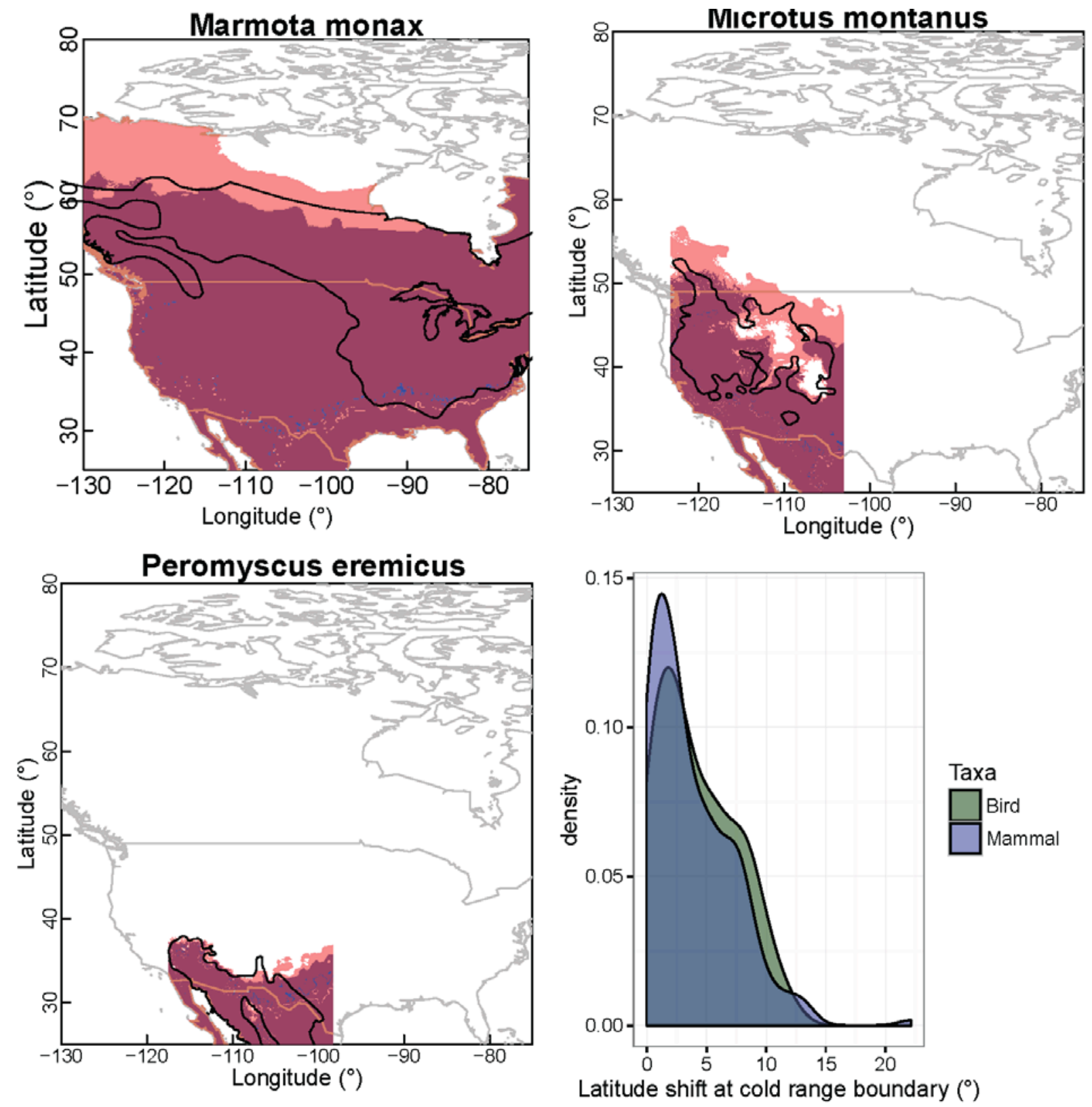

Figure 4. We depict observed cold range boundaries (black polygons: IUCN range maps) and those projected based on metabolic constraints for exemplar North American rodents in current (blue: 19502000) and predicted future (red: 2061-2080 from HadGEM2-AO model) climates ( $a-c)$. Purple shading indicates portions of the projected range occupancy that persists through climate warming. We note few areas of range contraction (blue). The species differ in the extent of their current distribution and the projected range expansion as a result of climate change (a, Marmota monax, groundhog; $b$, Microtus montanus, montane vole; and c, Peromyscus eremicus, cactus mouse). Projected based on metabolic constraints indicate that the majority of mammals (purple) and birds (green) will shift their cold range boundary modestly poleward through climate changes (d). However, numerous species are projected to shift their cold range boundary poleward by $10^{\circ}$ latitude and some species are projected to shift by as much as $22^{\circ}$. 